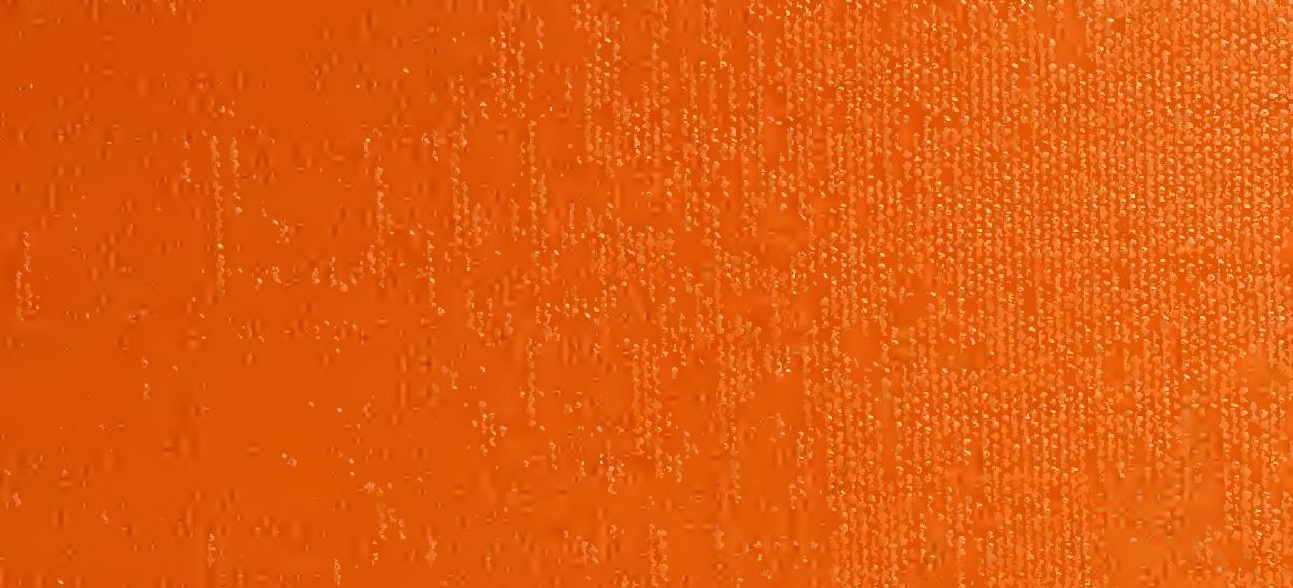

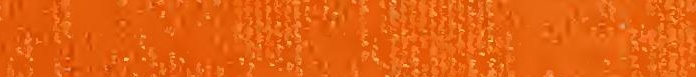

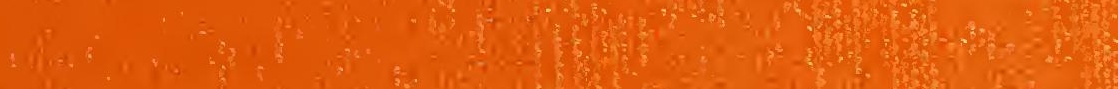

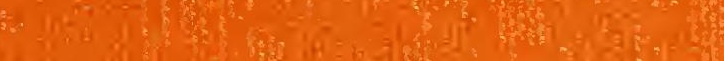

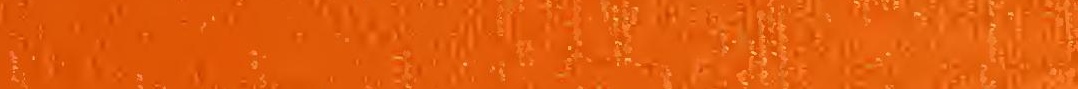

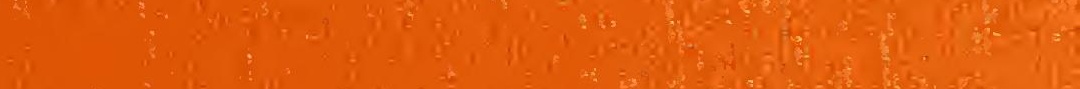

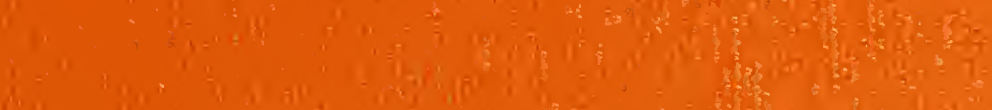

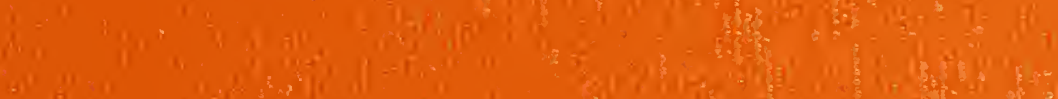

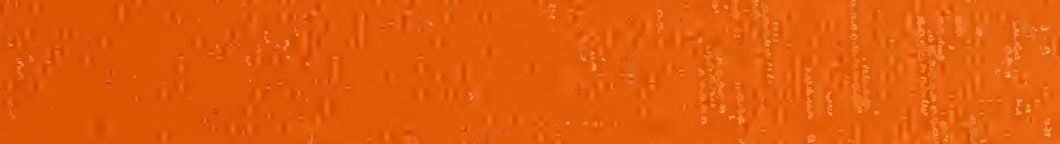

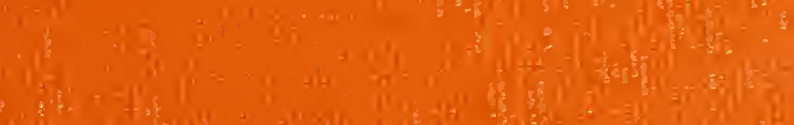

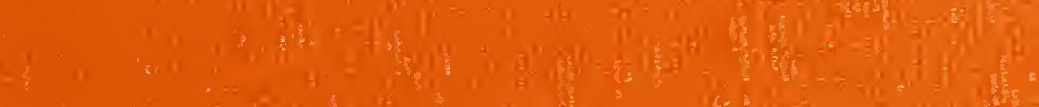

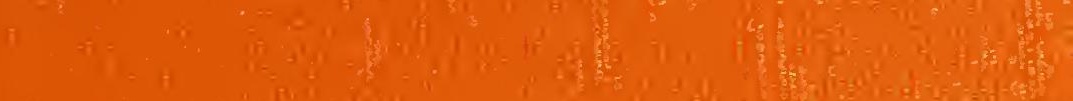

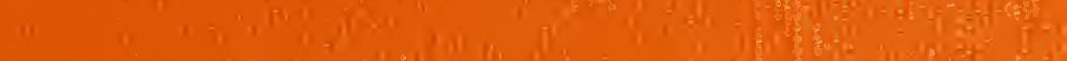

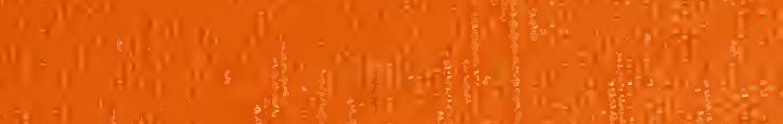
4.

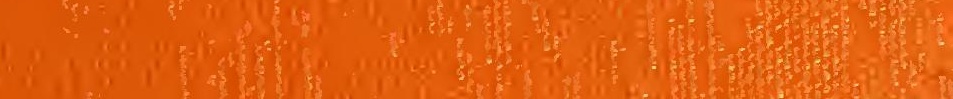
(1) (1)

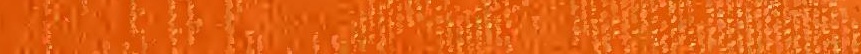

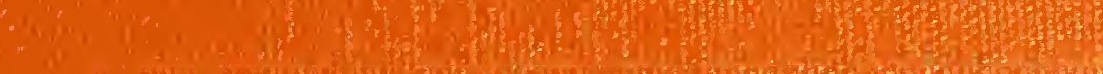

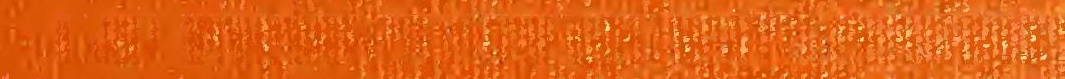

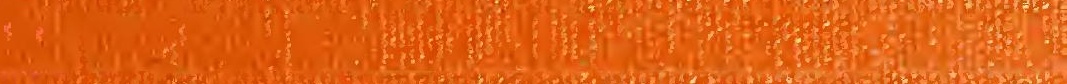

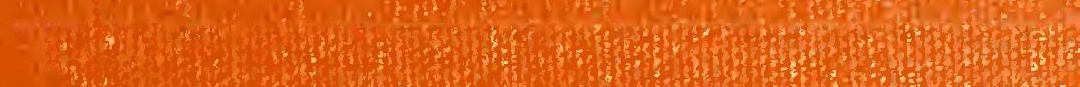

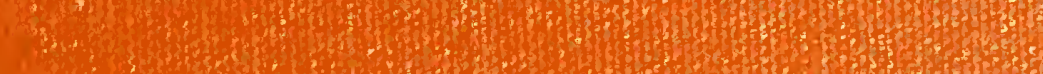

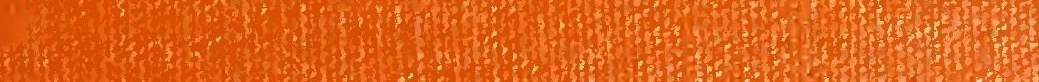
(5) S. H. ? n.t. 317.

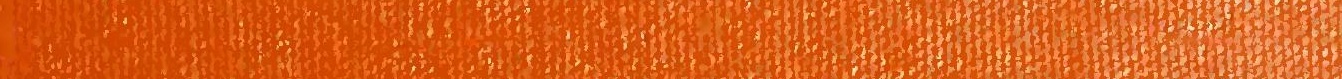
Lan (1.

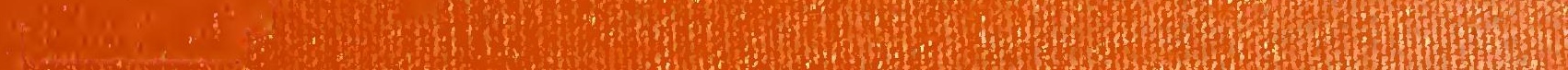

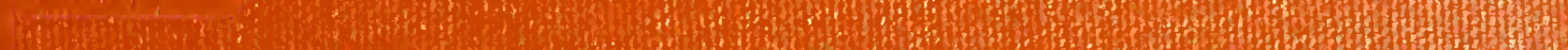



NBSIR 78-1536

\section{A Scaled-Down Version of the National Bureau of Standards Low Velocity Airflow Facility}

L. P. Purtell

Fluid Engineering Division

Center for Mechanical Engineering and Process Technology

National Engineering Laboratory

National Bureau of Standards

Washington, D.C. 20234

September 1978

Final

Prepared for

Department of Defense

Calibration Coordination Group

Working Group on Flow 



\section{A SCALED-DOWN VERSION OF THE NATIONAL BUREAU OF STANDARDS LOW VELOCITY AIRFLOW FACILITY}

L. P. Purtell

Fluid Engineering Division

Center for Mechanical Engineering and Process Technology

National Engineering Laboratory

National Bureau of Standards

Washington, D.C. 20234

September 1978

Final

\section{Prepared for}

Department of Defense

Calibration Coordination Group

Working Group on Flow

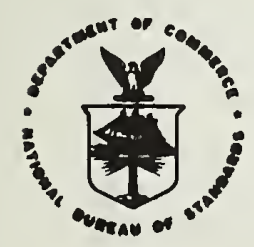

U.S. DEPARTMENT OF COMMERCE, Juanita M. Krops, Secrotary

Dr. Sidnoy Harman, Undor Secrotary

Jordan J. Baruch, Assistant Secretary for Science and Tochnology

NATIONAL BUREAU OF STANDARDS, Ernest Ambler, Director 


\title{
A SCALED-DOWN VERSION OF THE NATIONAL BUREAU OF STANDARDS \\ LOW VELOCITY AIRFLOW FACILITY
}

\section{P. Purtell}

\begin{abstract}
A scaled-down version of the National Bureau of Standards Low Velocity Facility for calibration of anemometers at low air velocities is presented. Included is an analysis of the quality of air flow to be expected, the instrumentation (a laser velocimeter) necessary for the velocity measurements, and estimates of the cost of components and materials. Enough detail is included to serve as a.preliminary design of the proposed facility.
\end{abstract}

\section{INTRODUCTION}

In response to a need for air flow measurements at very low velocities generated by concern for environmental quality and occupational safety and health, the National Bureau of Standards (NBS) has developed a calibration facility for the measurement of these low velocities. The construction of the facility required many design innovations since standard design guidelines are strictly applicable only at air speeds higher than those required of this facility. Likewise standard anemometers do not operate well at the lower velocities desired which required turning to the new technology of laser velocimetry. The laser velocimeter, linear from first principles and having high resolution, was thus chosen to be the velocity standard for the facility.

The successful construction of the NBS Low Velocity Airflow Facility led to an inquiry by the Department of Defense Calibration Coordination Group, Working Group on Flow, concerning the possibility of constructing a scaled-down version of the NBS facility for use in their own extensive calibration operations. This report, a feasibility study conducted by NBS for the Working Group on Flow, presents an analysis of the estimated performance of the wind tunnel, a study of the required laser velocimeter velocity standard, and a preliminary design of the wind tuniel and laser velocimeter. The basic goal of this study was to determine whether or not a scaled-down version of the NBS facility within the size limitations imposed (a volume, 30 feet long by 12 feet wide by 7 feet high) would perform satisfactorlly 
as a calibration facility. The design thus contains detail sufficient for this purpose but should also serve as a preliminary design since only some miror construction details were omitted. Estimations of equipment and special material costs are included, but construction (labor) costs are omitted since they would require the detailed final design.

\section{THE WIND TUNNEL}

The basic approach taken toward a wind tunnel design based on the NBS Low Velocity Airflow Facility was to scale down the size of all components of the facility except the mesh and cell sizes and streamwise dimensions and separations of the screens and honeycomb. Thus only the size of the air stream should be affected and not its quality (e.g., turbulence intensity). In addition the test section length was reduced to a size appropriate for calibrations and the entrance section was not tilted with respect to the centerline of the tunnel (as is the NBS tunne1) since this tilt was necessary in the NBS tunnel only to avoid excavating the floor of the building. Since the scaled-down tunnel would be elevated off the floor for most of its length, the supporting structures would be somewhat different in detail from the NBS tunnel but generally quite similar in construction.

Calibrating an intrusive anemometer requires, ideally, piacing the instrument in an airstream of infinite lateral extent so that the presence of the instrument in the airstream does not affect the air velocity far from the instrument. In practice, however, the airstream is confined to a finite width, either in a duct or a jet, and thus only approximates the ideal situation. This approximation becomes increasingly better as the size of the airstream increases relative to the size of the intruding anemometer. For a proposed calibration facility, then, the magnitude of this approximation must be estimated and subsequently a judgment made on the adequacy of the facility for calibrations.

Since the largest instrument to be considered for the scaled-down tunnel is a four-inch vane anemometer, such an instrument was chosen to evaluate the effects of a finite sized test section. Sufficiently far from an obstacle in an ideal flow the flow field may be approximated by that over a sphere of radius chosen to characterize the object. For the four-inch vane anemometer this radius was chosen to optimize the fit of actual velocity measurements upstream of the anemometer on the centerline of the tunnel to theoretical velocities upstream of a sphere having that radius. Knowing the radius of the sphere then permits computing velocities anywhere in the flow field around the sphere and using them as approximations to flow around the anemometer. 
The velocity upstream of a sphere in an ideal flow is given by

$$
\frac{\mathrm{U}}{\mathrm{U}_{\infty}}=1-\left(1+\frac{\mathrm{x}}{\mathrm{r}}\right)^{-3}
$$

where $U$ is the streamwise component of velocity, $U_{\infty}$ the velocity far upstream of the sphere, $\mathrm{r}$ the radius of the sphere, and $\mathrm{x}$ the distance upstream from the surface of the sphere. Figure 1 presents some measurements at two air speeds of the streamwise velocity upstream of the anemometer and on the centerline of the tunnel and of the anemometer. Also plotted ( $x$ 's) are theoretical velocities upstream of a sphere (radius $5.63 \mathrm{~cm}$ ) at the same location as the anemometer. Note that the curves are quite similar for distances beyond about $5 \mathrm{~cm}$ from the surface of the sphere.

To investigate the effects of a finite flow field, then, the flow around the $5.63 \mathrm{~cm}$ sphere can be examined since it approximates the flow around the anemometer. The streamwise velocity at a distance $y$ from the centerline measured from the center of the sphere is given by

$$
\frac{\mathrm{U}}{\mathrm{U}_{\infty}}=1+\frac{1}{2}(\mathrm{y} / \mathrm{r})^{-3}
$$

That this expression with $\mathrm{r}=5.63 \mathrm{~cm}$ is also a good approximation to the flow around the anemometer was verified by computing the streamwise velocity at $\mathrm{y}=22.86 \mathrm{~cm}$ (nine inches) and comparing that to a measured value at that position. The common result was $\mathrm{U} / \mathrm{U}_{\infty}=1.007$. Equation (2) is plotted in Figure 2 which shows the rapid fall-off of $\mathrm{U} / \mathrm{U}_{\infty}$ from high values near the sphere toward 1.0 far from the sphere. Since in an infinite flow field $U / U_{\infty}=1.007$ at $\mathrm{y}=9$ inches, some interaction between a wall at that position and the flow nearer the sphere would be expected, but the effect on the calibration should be small, and since $\left(U / U_{\infty}-1\right)$ varies with the characteristic radius cubed, the effect on anemometers smaller than the four-inch vane anemometer should be imperceptible.

Based on the above considerations a test section of eighteen inches in width should be the minimum, and since this is also the maximum that is to be considered, the basic linear scaling for the tunnel design was fixed at one-half since the NBS tunnel has a test section $36 \times 36$ inches.

Figure 3 presents the overall layout of the proposed wind tunnel. Though the design is.meant to be schematic, it should easily serve as 
a preliminary design since it lacks only some details for the construction. The basic goal of the layout was to determine whether or not a 1/2-scale design could fit within the limits imposed on the size of the facility. All aspects of the NBS tunnel not pertinent to the proposed tunnel (such as an extensive test section) were omitted from the design.

The proposed tunnel has three sections: the flow conditioning section, the test section, and the drive section. The flow conditioning section consists of the entrance, honeycomb, screens, and contraction. The drive section consists of a square-to-round transition, the fan, and a diffuser. The following paragraphs detail construction considerations necessary to ascertain the feasibility of the proposed tunnel and to serve as a preliminary design and basis for rough cost estimation.

\section{THE ENTRANCE}

The entire flow conditioning section should be constructed of wood lined with tempered hardboard. The interior joints should be sealed airtight with glass fiber cloth and sanded smooth. Wood is the preferred material because of its natural vibration absorption quality and because of the ease of forming the curved supports for the hardboard.

The entrance should be fitted with a framework to hold a bank of air filters (Figure 4) to control dust entry into the flow. The smaller particles of ambient dust are necessary for laser velocimeter operation, but the larger particles should be removed. Ordinary household furnace filters are used in the NBS facility.

\section{THE HONEYCOMB AND SCREENS}

The honeycomb flow-straightener consists of a 3 inch thick sheet of phenolic with $3 / 8$ inch hexagonal cells (Figure 5). This sheet should be mounted in grooves in the walls as indicated in Figure 5 to minimize disturbance of the flow.

The screens (to reduce the scales of the turbulence) should be 24-inch mesh 7.5 mil stainless steel wire mounted in wooden frames (Figure 5). These frames should also be mounted in grooves in the walls as indicated. Though the details of the construction are subject to modification, the spacing between the screens and between the first screen and the honeycomb should not be changed. 


\section{CONTRACTION}

The contours of the interior surface of the contraction are presented in Figure 6. These are scaled down by one-half from the NBS tunnel. The interior surface should be faired smoothly between the curves and the adjoining flat sections (the screen housing and the test section).

\section{TEST SECTION}

To accomodate a laser velocimeter the walls of the test section should be constructed of a good quality clear acrylic. The section is square in cross section, 18 inches between walls (at all locations) and 48 inches long (Figure 7). The framework should be metal to minimize its size since the frame blocks light transmission through the test section. For user convenience both side walls should be removable for access to the interior. The test section is suspended from beams which rest on columns near the fan and on the framework of the contraction. This allows clearance for the laser velocimeter traverser to be located beneath the tunnel. Support of the test section at the downstream end simply by the transition section and fan is not possible because of a flexible coupling between the transition section and the fan to isolate fan vibrations from the test section.

\section{SQUARE-TO-ROUND TRANSITION}

Since the test section is square and the fan housing is round, a transition section fabricated from sheet metal is necessary. Flanges should be attached around both perimeters and along its length (Figure 8 ) to maintain its shape. The downstream end should be attached to a flexible coupling (e.g., neoprene gasket material) attached in turn to a flange on the fan.

\section{THE FAN}

Since the pressure drops through the screens and honeycomb are the major factors in the pressure drop through the tunnel and since these pressure drops will be approximately the same for the proposed tunnel and for the existing NBS tunnel (at a given speed) the required pressure rise across the fan for the proposed tunnel was computed by scaling the pressure rise in the existing tunnel. Thus the following specifications were compiled for the fan:

1.5 inches water pressure differential at $5000 \mathrm{cfm}$

3.0 inches water pressure differential at $6750 \mathrm{cfm}$ 
The first specification would apply to a fan providing a top speed of approximately $37 \mathrm{fps}$ and the second to a fan providing a top speed of approximately $50 \mathrm{fps}$. Since the required powers are approximately 2 and $5 \mathrm{HP}$, respectively, the costs will be quite different. Also the fan may be direct drive or belt driven which will also affect the cost. Experience at NBS has only been with the direct drive, but no problems are foreseen with using the belt drive, which may be much less expensive. The units should be powered from an AC to DC solid-state converter employing $1 \%$ speed control.

\section{THE DIFFUSER}

A diffuser downstream of the fan will serve to reduce noise and improve the performance of the fan. Assuming that a wall may be located approximately six feet from the exit of the fan, little improvement (and perhaps degradation) of the flow could be expected by a diffuser longer than shown in Figure 9. The construction of the diffuser should be of wood and hardboard similar to the entrance section, though here the glass cloth may be omitted from the joints.

\section{LASER VELOCIMETER VELOCITY STANDARD}

For a number of reasons the laser velocimeter is by far the best instrument for measuring very low fluid velocities in the laboratory. It is nonintrusive, linear, and can have high resolution. A calibration determined at a high, and thus easily resolvable, speed is valid throughout the measuring range of the instrument. Today laser velocimeters in configurations suitable for various flow configurations are commercially available which provide for convenient maintenance and replacement (or expansion) parts if needed.

The particular type of system analyzed here for application to mean flow measurements in the proposed tunnel consists of a single channel, dual beam, forward scatter optical system and a frequency tracking (PLL) signal processor with digital data validation and analog output meter. Once installed the system should be easy to operate and reasonably maintenance free. Various types of systems are commercially available and many may be suitable for the proposed facility. The one analyzed here was chosen simply to assess the feasibility of assembling a laser velocimeter from commercially available items with capabilities sufficient for the desired calibrations.

\section{OPTICAL SYSTEM}

The optical system considered (Figure 10) consists of a $\mathrm{He}-\mathrm{Ne}$ laser, of at least $15 \mathrm{mw}$ power, projecting and receiving optics, and a photomultiplier tube assembly, all standard commercial items. The 
Incident laser beam is split by a glass beam-splitter, the resulting beams focused to an intersection within the test section, and light scattered from the intersection collected by the receiving optics. For the recommended optics with a $600 \mathrm{~mm}$ focusing lens the intersection volume has approximate dimensions of $0.7 \mathrm{~mm}$ in diameter by $26 \mathrm{~mm}$ in length, the long dimensions along the optical axis of the system (i.e., trnasverse to the flow). The optics need to be mounted rigidly on supports such as discussed in Section 13.

\section{SIGNAL PROCESSING}

The signal from the photomultiplier tube consists of bursts of frequency data which must be converted to velocity data (the velocity is proportional to the frequency). The processor analyzed here utilizes phase locked loop circuitry to "capture" a burst which is then converted from frequency to voltage. A digital counter guarantees a minimum number of cycles without drop-out.. The analog output meter may be adjusted to read the voltage in any desired units of "velocity" for convenient reading of data though this may reduce the resolution of the system. The meter also averages data with time (two settings of damping).

The proportionality factor between frequency and velocity should remain very nearly constant with time providing the optics are not moved. Thus, knowing this factor, the electronics can be checked and adjusted as desired by simply connecting a known frequency to the input of the processor and adjusting the meter to read the appropriate velocity.

The resolution of the recommended system is presented in Figure 11. It was computed assuming a direct reading of voltage which gives the maximum attainable resolution for the system. A resolution of $1 \%$ is attained at $15 \mathrm{fpm}$, improves rapidly above this speed, and reaches $1.5 \%$ at $10 \mathrm{fpm}$. If the meter is adjusted for "velocity" units the resolution will be improved by using a separate voltmeter with higher resolution limited only by the frequency to voltage conversion within the processor. An oscilloscope is a highly desirable accessory for determining and adjusting the quality of the laser velocimeter performance. They are readily available with specifications adequate to handle all signals to be encountered and can include storage capability which is necessary to view the random bursts of data.

\section{TRAVERSER}

The optics for the laser velocimeter must be held rigidly in place to hold the intersection angle fixed and to maintain proper focusing of the scattered light onto the photomultiplier tube. However, the probe volume needs to be movable to measure velocity profiles within the duct both with and without anemometers mounted in it. Thus a traverser is 
desirable which will hold the optical components fired with respect to the duct. A preliminary design of such an apparatus is presented in Figures 12 and 13. The primary goal of the design was to determine the space required for such a device yet provide enough detail to permit a final design to be completed. The traverser as designed could locate the focal volume virtually anywhere in the duct. The optical system, including the laser, is mounted on a rigid platform which can be moved vertically on ball bushings/shafts driven by a screw. This assemble is mounted on a frame which rides on ball bushings/shafts transverse to the duct, all of which rides on ball bushings/shafts laid on the floor beneath the tunnel parallel to the flow. The two horizontal motions could be either motor or hand drive.

\title{
14. LIST OF EQUIPMENT AND POSSIBLE SUPPLIERS
}

The calibration facility may be conveniently divided into two subsystems: the wind-tunnel and the laser velocimeter. The cost of the latter can be estimated except for the labor necessary to construct the traverser and to set up and adjust the optical components. The cost of the wind tunnel, however, is mostly in the labor to construct it and is difficult to estimate without a final design and consultation with carpentry estimators. The following estimates, therefore, are of materials and equipment only. Several possible suppliers are listed, but others may be available; the listings are meant to be representative and do not imply an endorsement.

\subsection{The Wind Tunnel}

\subsubsection{The Fan}

The choice of the type of fan (belt driveor direct drive) and of the maximum air speed ( 37 or $50 \mathrm{fps}$ ) will determine the cost of the fan. The cost for a maximum air velocity of $50 \mathrm{fps}$ will be from $\$ 5000$ to $\$ 8000$. The cost for a maximum air velocity of $37 \mathrm{fps}$ will be from $\$ 2500$ to $\$ 5000$. Two possible suppliers are:

\author{
Buffalo Forge Company \\ Buffalo, New York \\ Joy Manufacturing \\ New Philadelphia, Ohio
}

Local offices are in many cities. 
14.1.2 Honeycomb

A glass-filled phenolic honeycomb is available which costs approximately $\$ 500$ for a sheet $3-1 / 2$ feet by 8 feet. One possible supplier is:

\author{
Hexcel Corporation \\ 11711 Dublin Boulevard \\ Dublin, CA 94566
}

\title{
14.1.3 Screens
}

Pieces of screening about 4 feet by 4 feet are available at. approximately $\$ 25$ each. One possible supplier is:

C-E Tyler, Screening Division

8200 Tyler Boulevard

Mentor, OH 44060

\subsection{Laser Velocimeter}

\subsubsection{Optics}

Many suppliers of optical components are available, but ease of assembly would dictate purchase of optically and mechanically compatible modules. The total cost will be approximately $\$ 5500$. Two possible suppliers are:

Thermo-Systems Incorporated

Box 3394

St. Paul, MN 55165

DISA Electronics

779 Susquehanna Avenue

Franklin Lakes, NJ 07417

14.2.2 Signal Processor

The suppliers listed for opties also supply processors. The cost will be approximately $\$ 8000$. Other suppliers may be available.

\subsubsection{Laser}

Many suppliers of lasers are available selling many different types and powers of lasers. The total cost depends on.options, power, and quality, varying from $\$ 3000$ to $\$ 8000$. Two possible supplier are: 
Spectra-Physics Incorporated

1250 W. Middlefield Road

Mountain View, CA 94042

Jodon Engineering Associates, Inc.

145 Enterprise Drive

Ann Arbor, MI 48103

\subsubsection{Oscilloscope}

The cost will be about $\$ 3000$. Two possible suppliers are:

Tektronix

P.0. Box 500

Beaverton, Oregon 97005

Hewlett-Packard

1820 Embarcadero Road

Palo Alto, CA 94303

\section{SUMMARY}

From the analysis of blockage effects within the $18 \times 18$ inch test section, from the study of available laser velocimeter performance, and from the preliminary design of the wind tunnel, it is concluded that construction of a calibration facility within the required size and performance limitations is feasible. As with all design extrapolations (the tunnel is smaller than any others built for this speed range) there is some risk that problems may be encountered, but the analysis contained herein indicates that it is minimal.

The preliminary designs are primarily aimed at assessing feasibility of construction but include enough detail that a final design can be completed. Estimated costs for the facility are only for equipment and special materials since construction (labor) costs would be difficult to estimate without a detailed final design. 


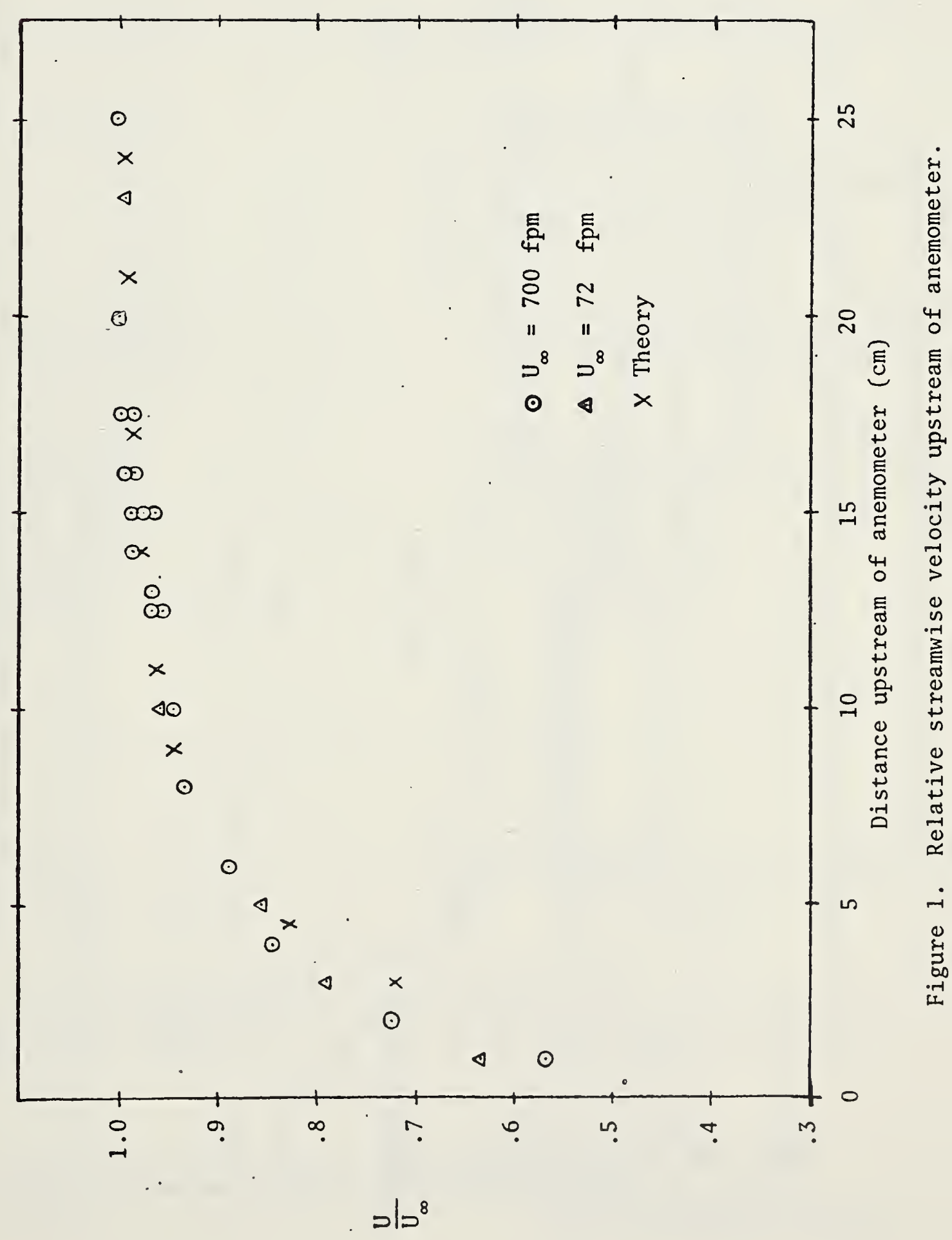




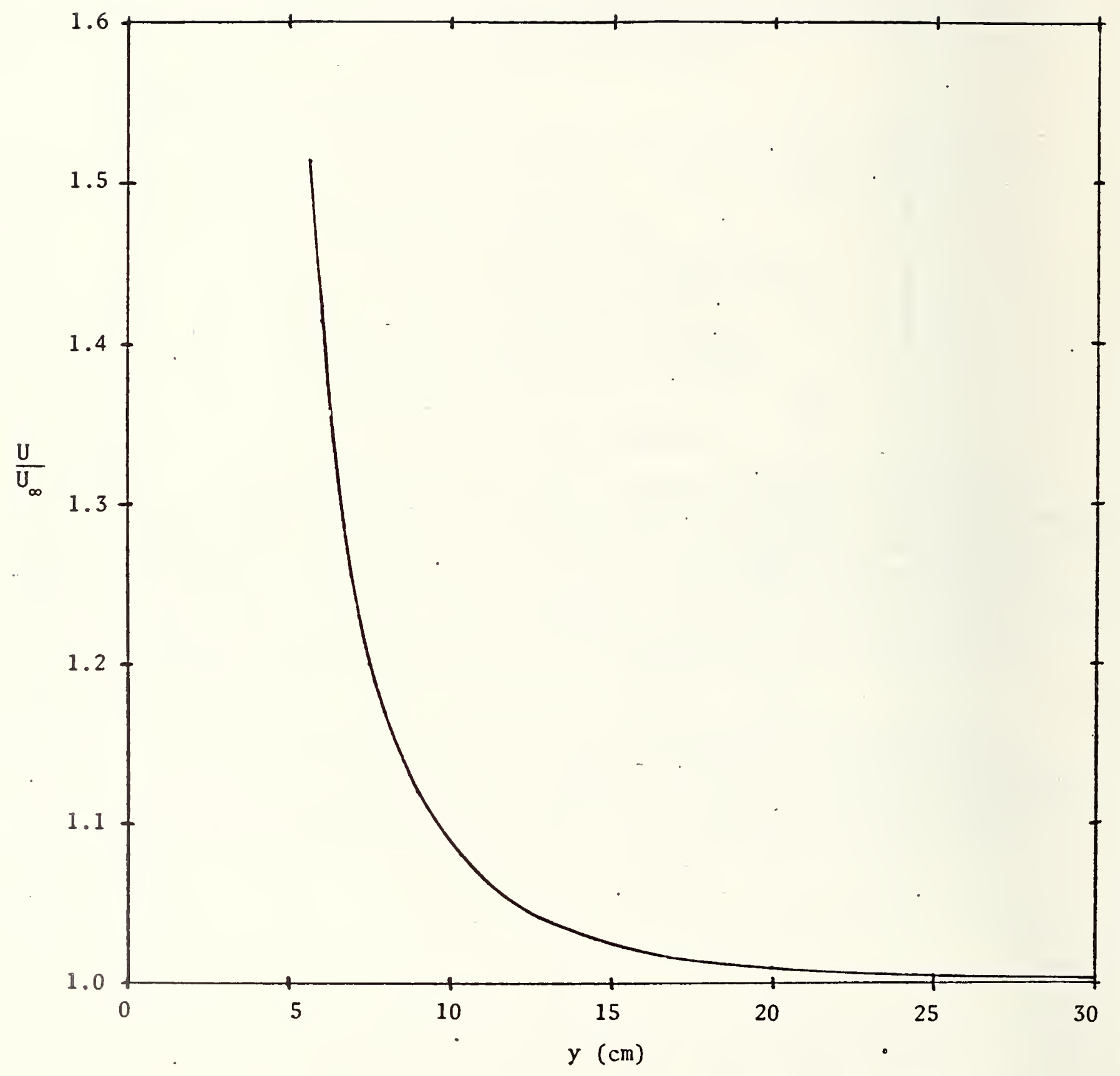

Figure 2. Theoretical relative streamwise velocity as function of distance, $y$, measured transverse to mean flow and from center of sphere. 

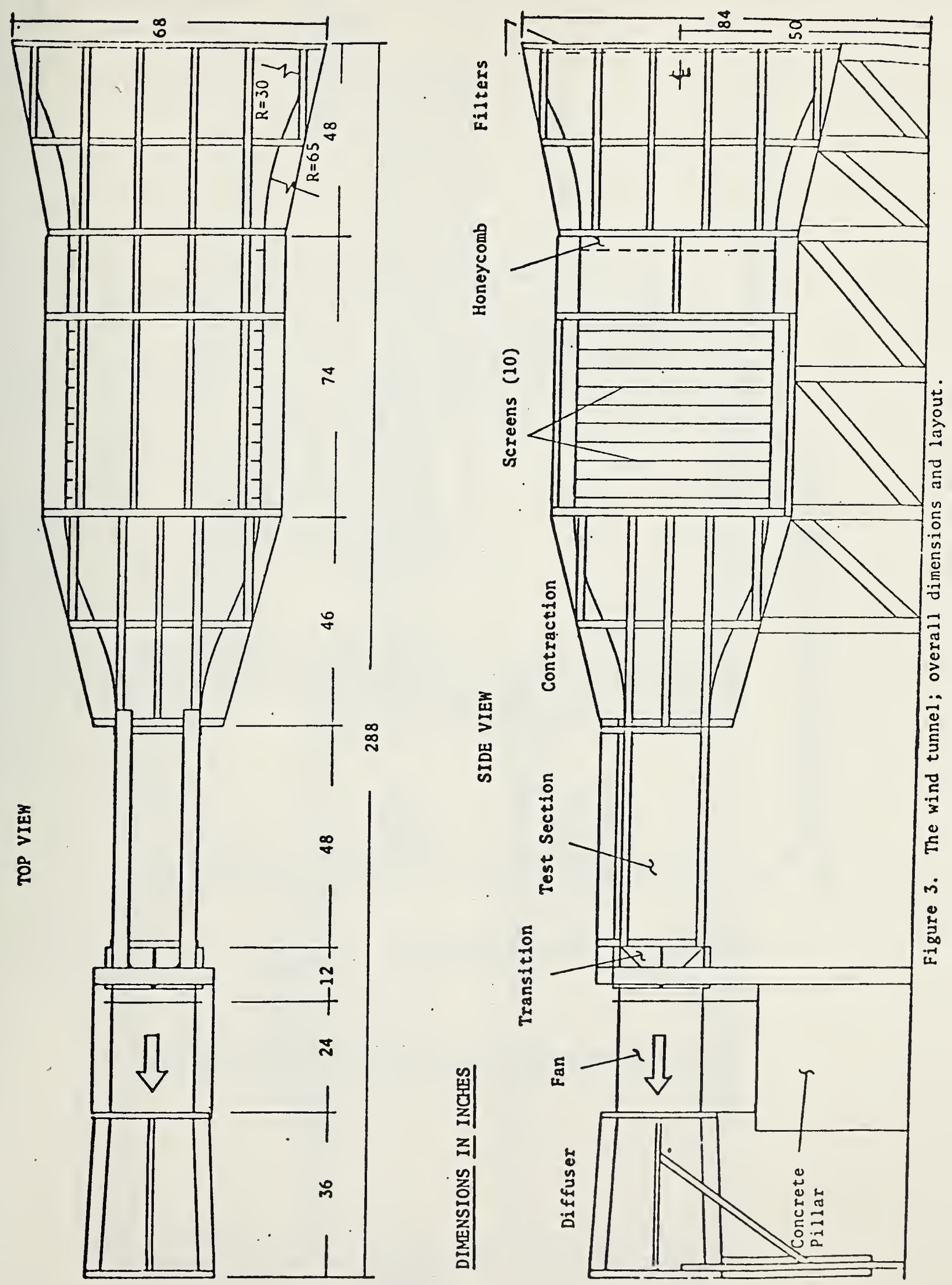


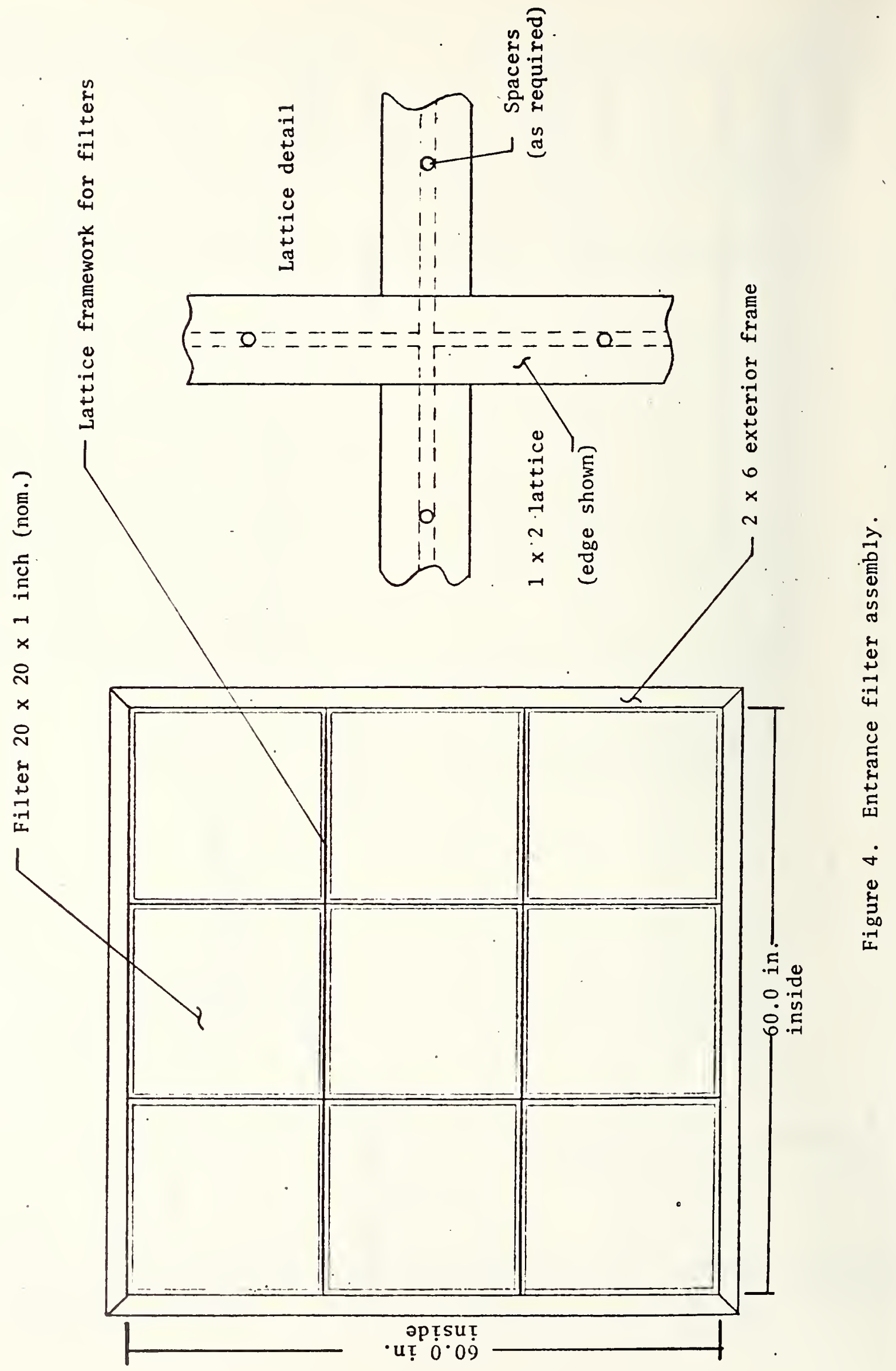




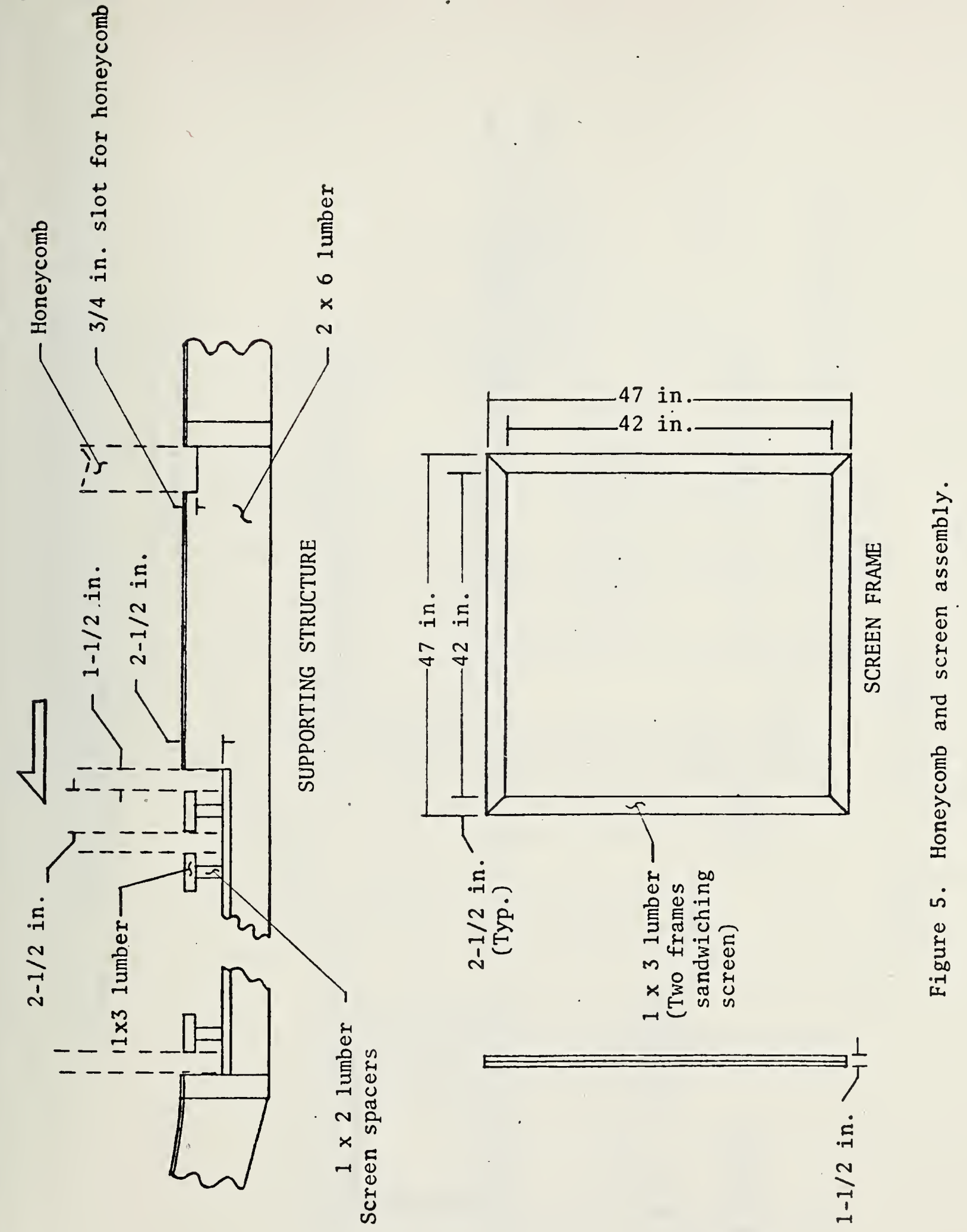




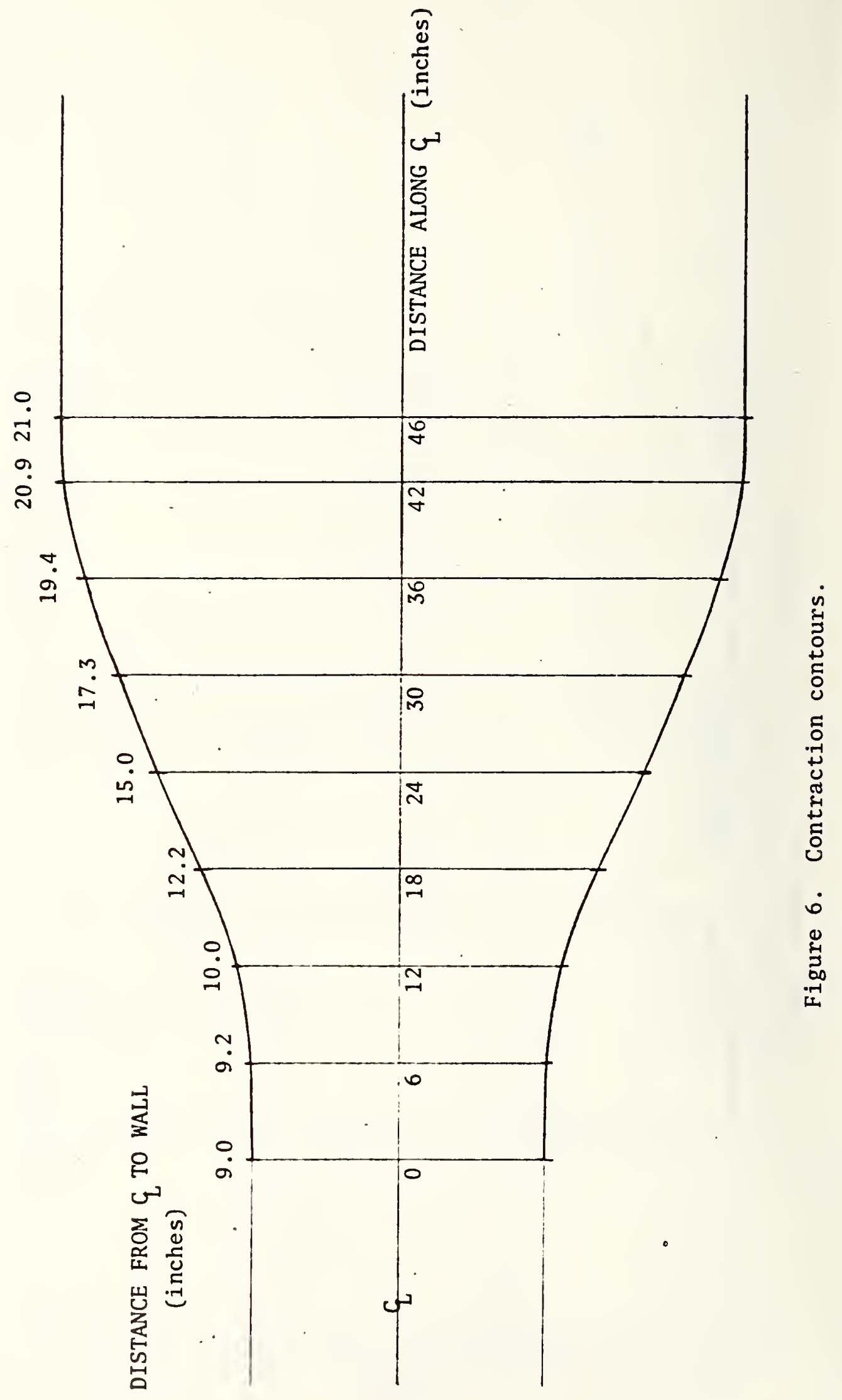



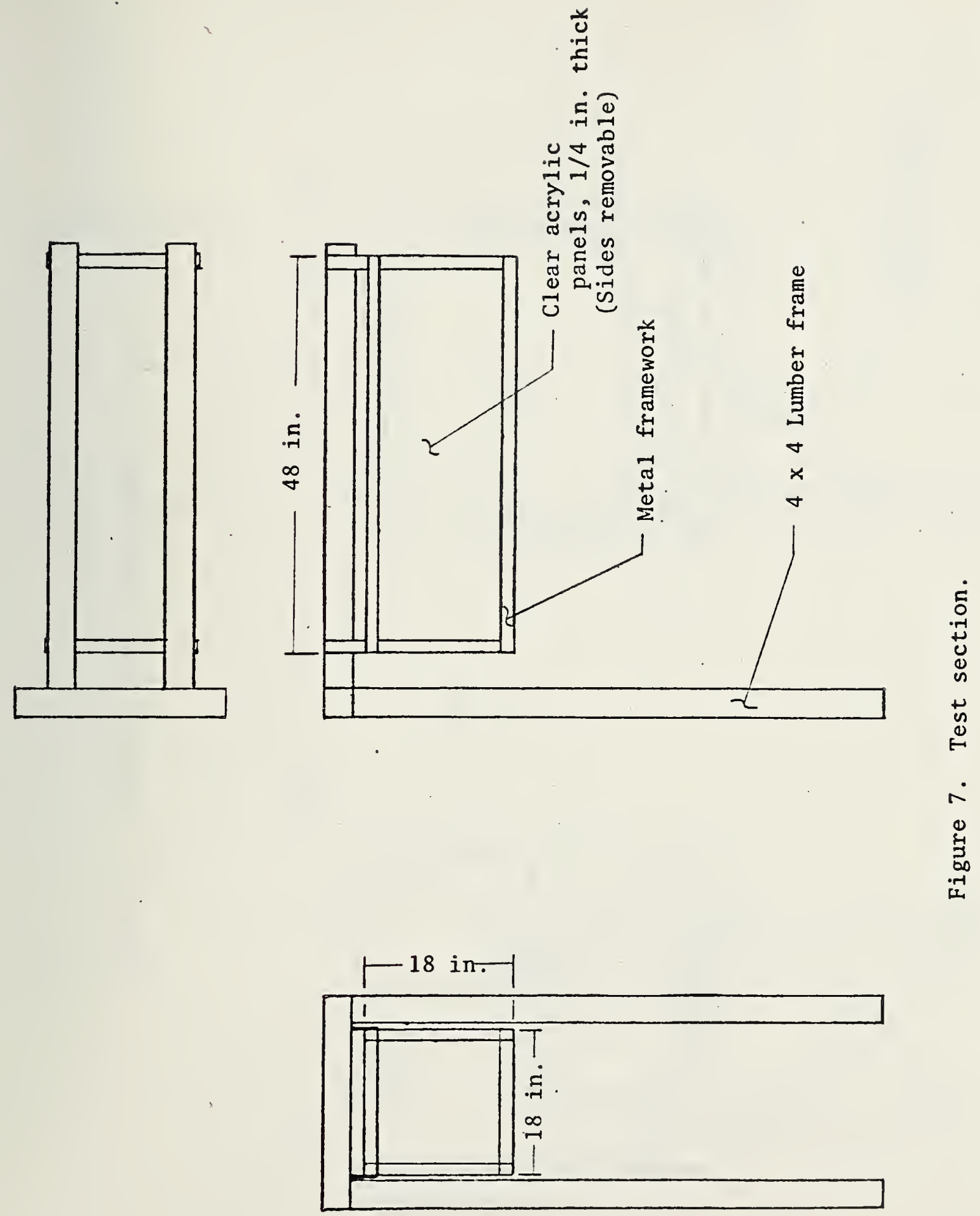

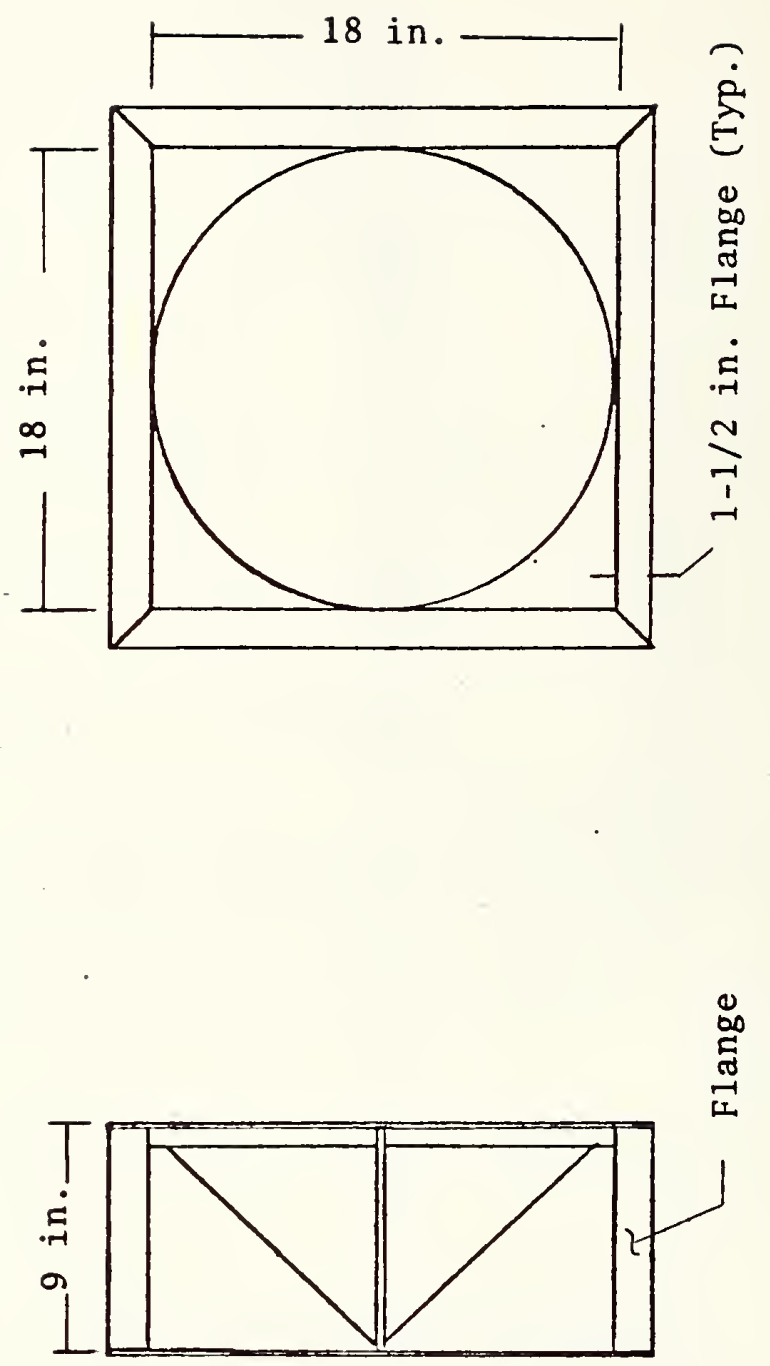

品

D
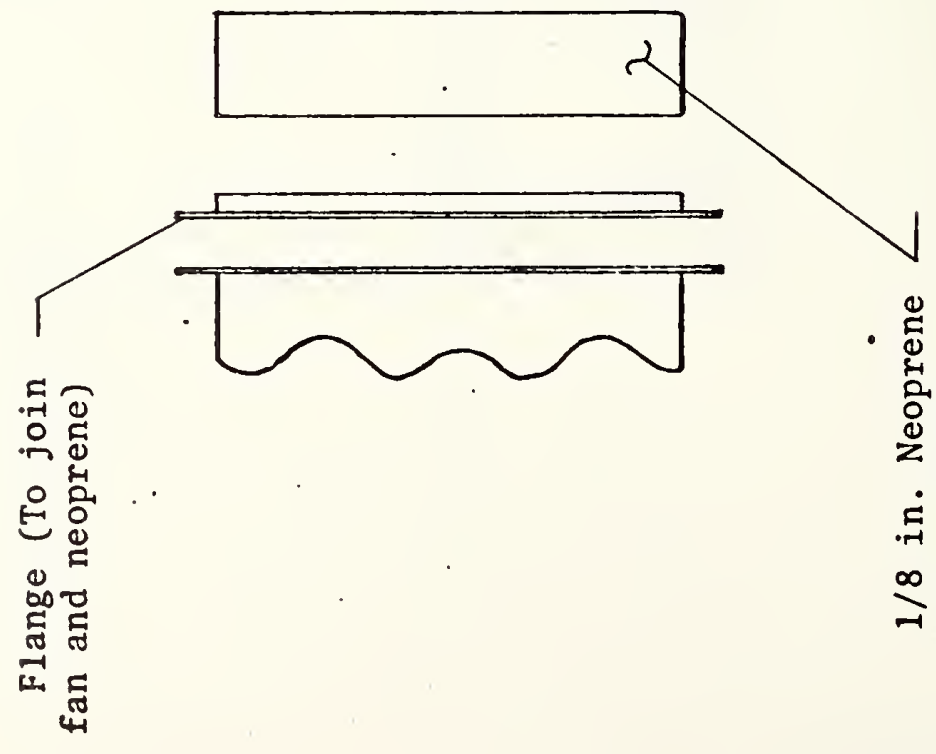

-

응

之.

.

$\stackrel{-1}{-1}$ 


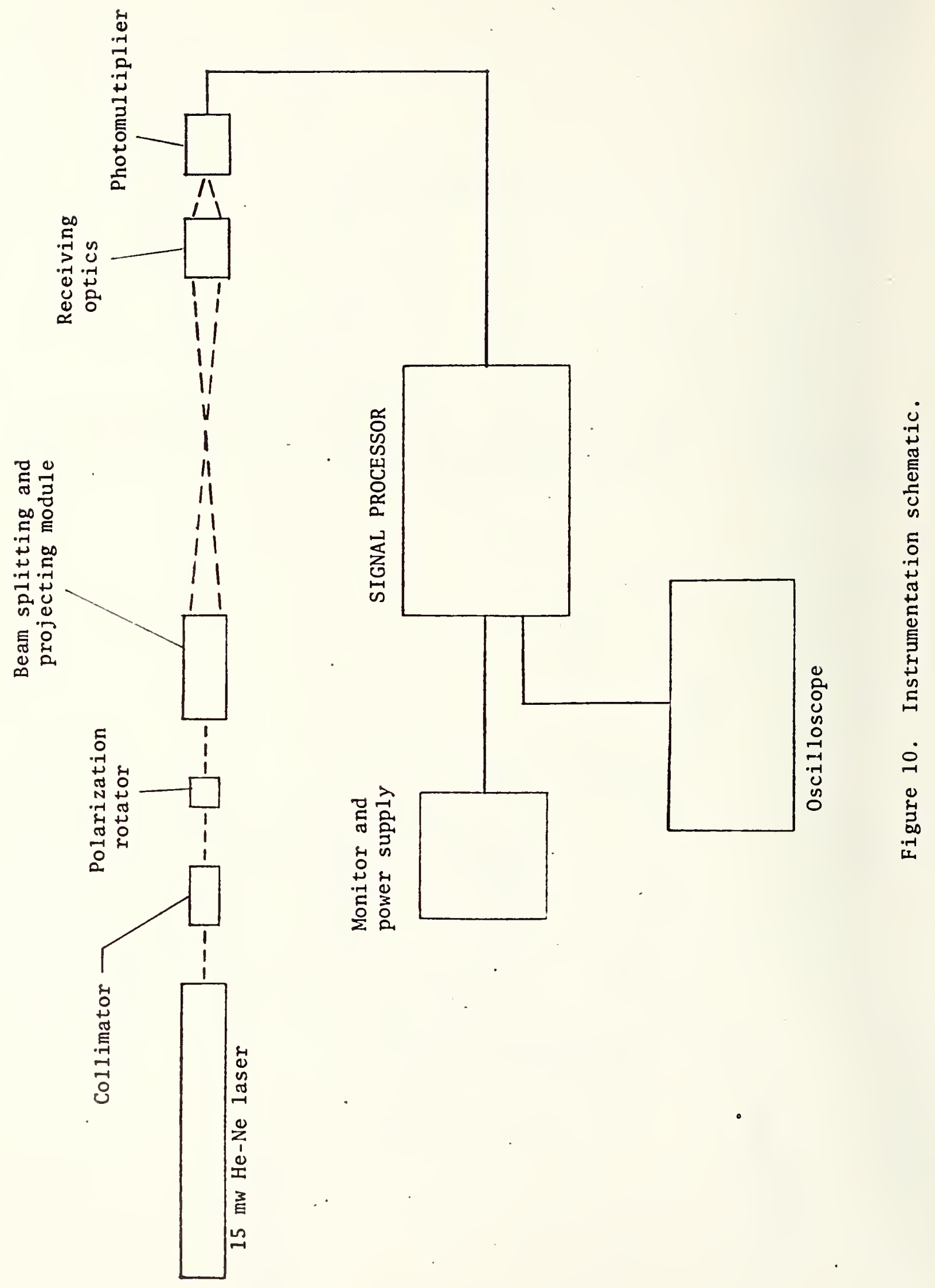




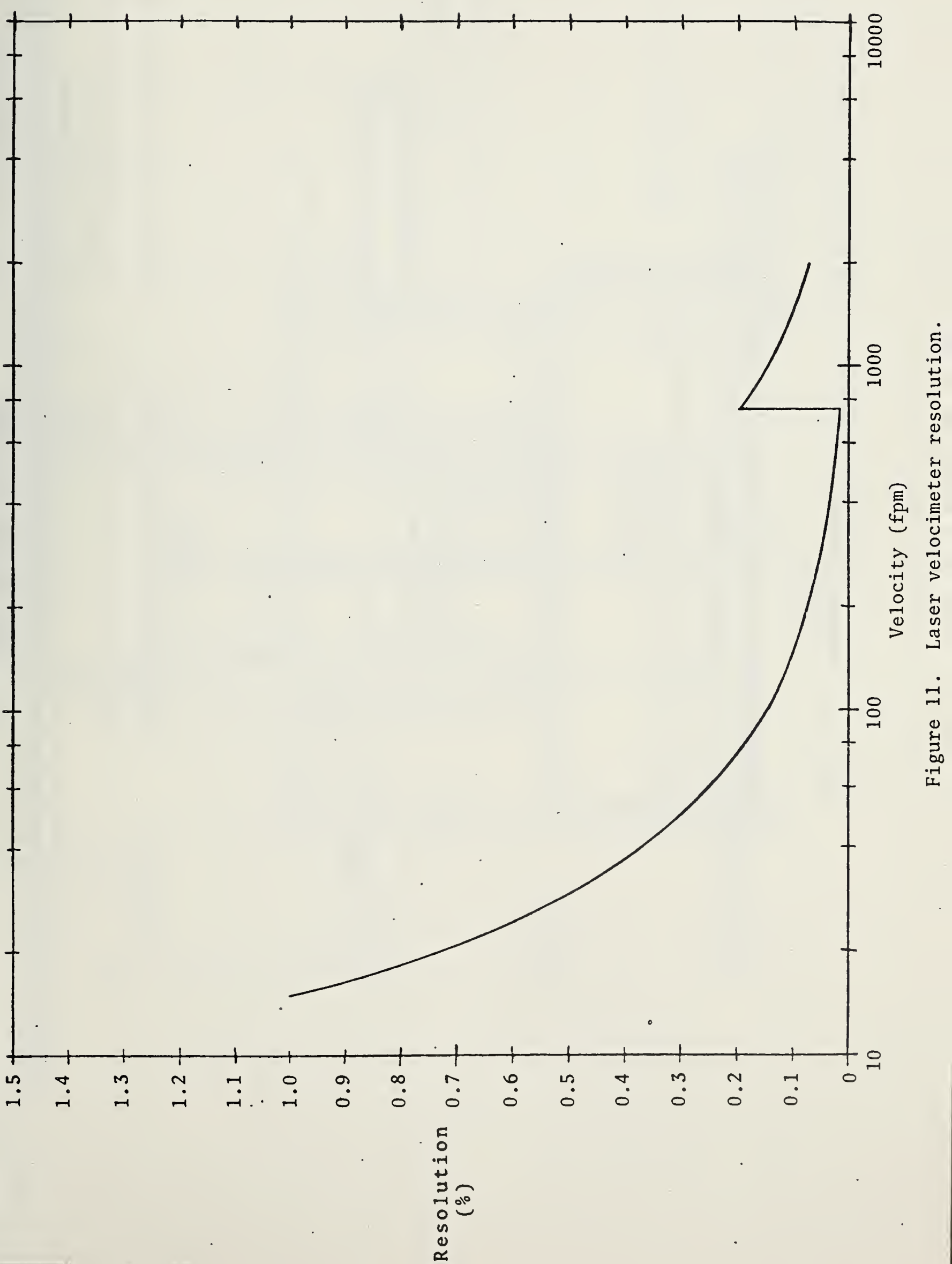




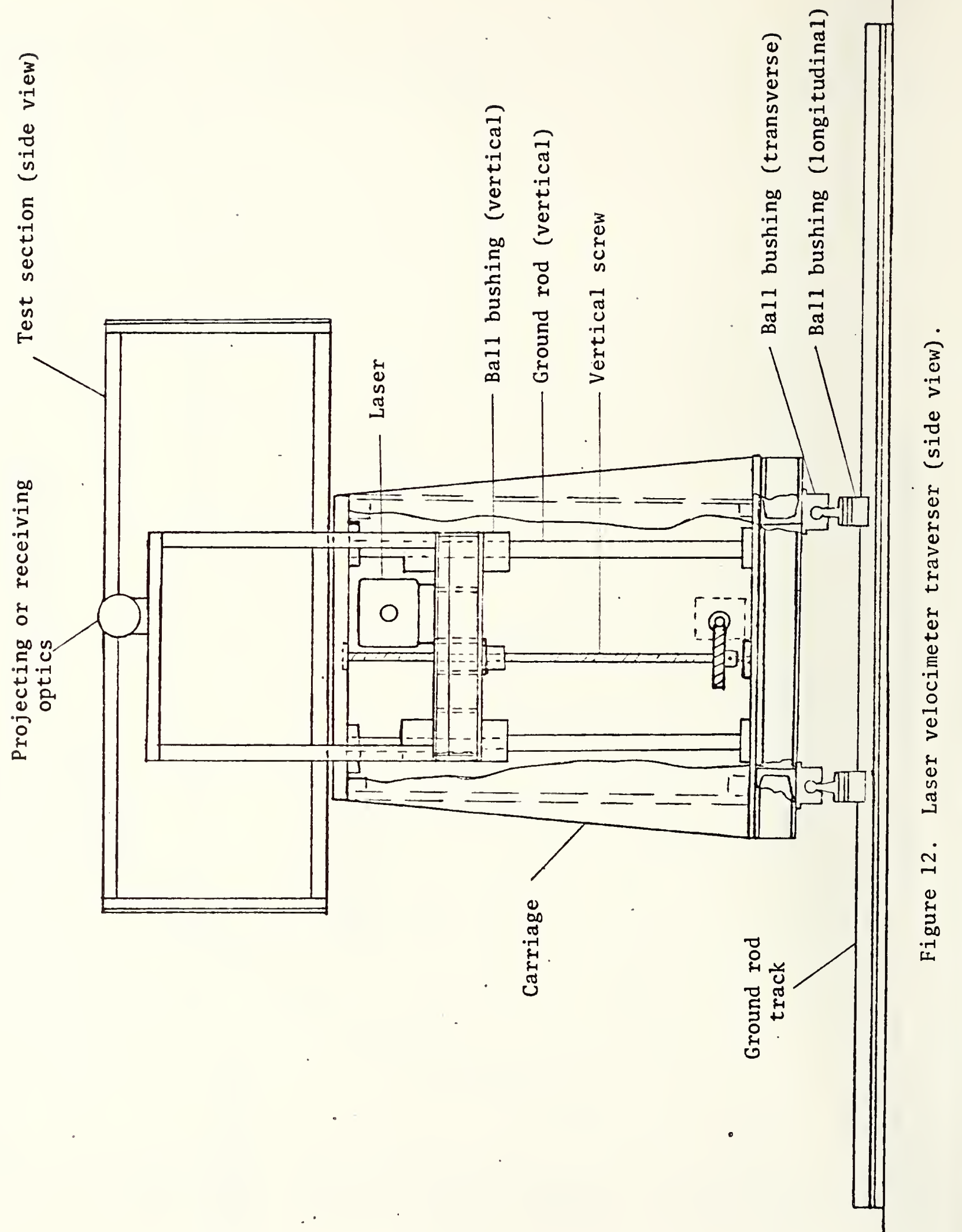




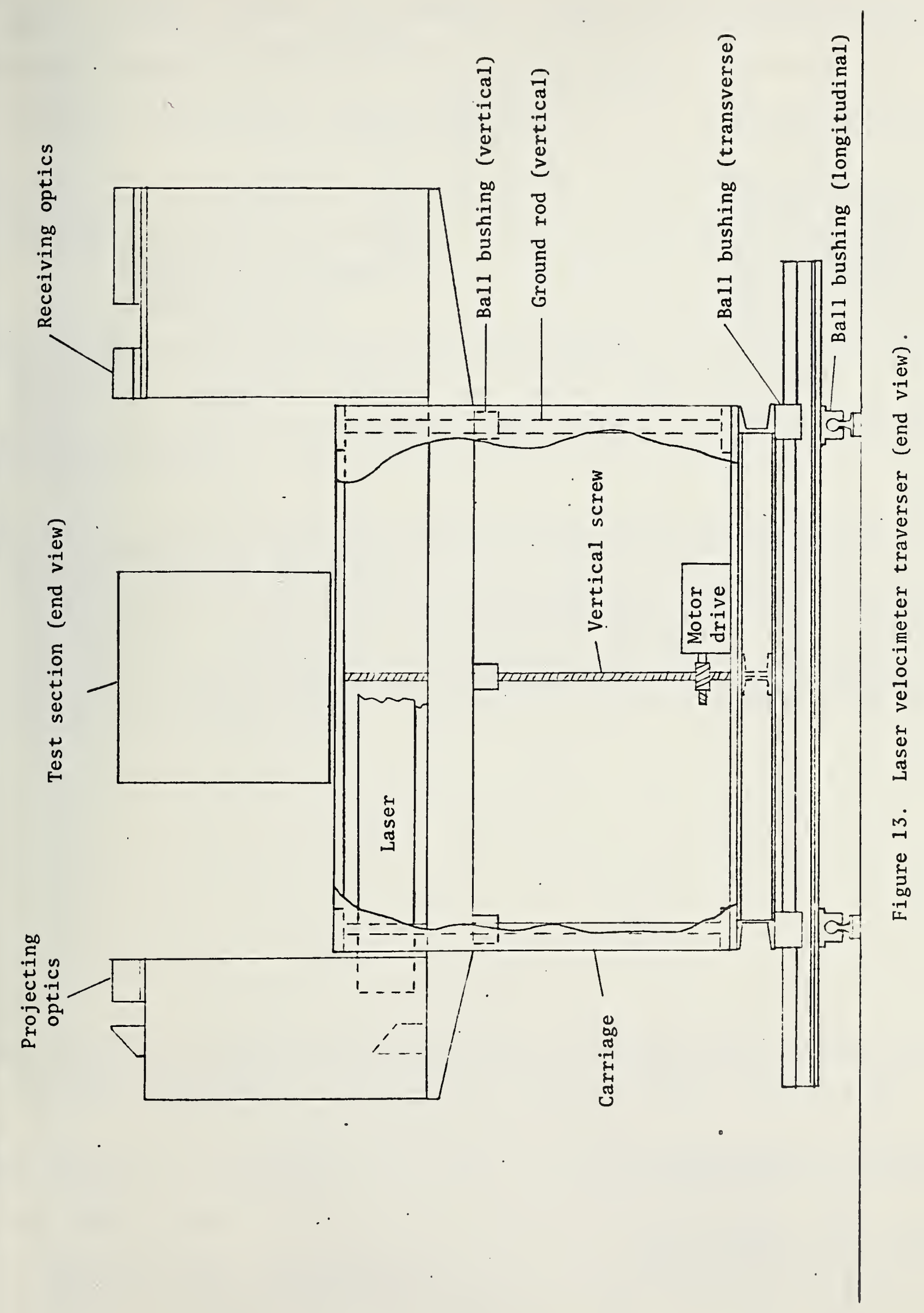




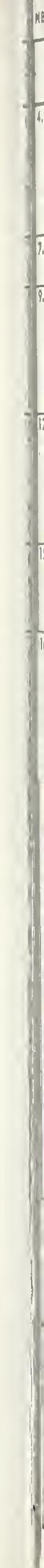


U.S. DEPT. OF COMM. BIBLIOGRAPHIC DATA SHEET

1. PUBLICATION OR REPORT NO.
NBSIR $78-1536$

NBS IR $78-1536$
2. Gov't Accession No.

3. Recipient's Accession No.

5. Publication Date

A SCALED-DOWN VERSION OF THE NATIONAL BUREAU OF STANDARDS LOW VELOCITY AIRFLOW FACILITY

6. Performing Organization Code

8. Performing Organ. Report No.

L. P. Purte 11

7. $A$ UTHOR(S)

9. PERFORMING ORGANIZATION NAME AND ADDRESS

\section{NATIONAL BUREAU OF STANDARDS \\ DEPARTMENT OF COMMERCE \\ WASHINGTON, D.C. 20234}

12. Sponsoring Organization Name and Complete Address (Street, City, State, ZIP)

Department of the Air Force

HQ Aerospace Guidance and Metrology Center (AFLC)

ATTN: MLPM ( $\mathrm{Neu}$ )

Newark Air Force Station, Newark, Ohio 43055 NBSIR 78-1536

10. Project/Task/Work Unit No. 2130489

11. Coniract/Grant No.

CCG Project No.

$77-103$

13. Type of Report \& Period Covered

Fina 1

14. Sponsoring Agency Code

15. SUPPLEMENTARY NOTES

16. ABSTRACT (A 200-word or less factual summary of most significant information. If document includes a significant bibliography or literature survey, mention it here.)

A scaled-down version of the National Bureau of Standards Low Velocity Airflow Facility for calibration of anemometers at low air velocities is presented. Included is an analysis of the quality of air flow to be expected, the instrumentation (a laser velocimeter) necessary for the velocity measurements, and estimates of the cost of components and materials. Enough detail is included to serve as a preliminary design of the proposed facility.

17. KEY WORDS (six to twelve entries; alphabetical order; capitalize only the first letter of the first key word unless a proper name; separated by semicolons)

Airflow; anemometers; calibration; facility; laser; low velocity.

\section{AVAILABILITY}

XX For Official Distribution. Do Not Release to NTIS

Order From Sup. of Doc., U.S. Government Printing Office Washington, D.C. 20.402, SD Stock No. SNO03-00\}

Order From National Technical Information Service (NTIS) Springfield, Virginia 22161

\begin{tabular}{|l|l|}
\hline $\begin{array}{l}\text { 19. SECURITY CLASS } \\
\text { (THIS REPURT) }\end{array}$ & 21. NO. OF PAGES \\
UNCL ASSIFIED & \\
\hline $\begin{array}{l}\text { 20. SECURITY CLASS } \\
\text { (THIS PAGE) } \\
\text { UNCLASSIFIED }\end{array}$ & 22. Price \\
\hline
\end{tabular}


15 6434 


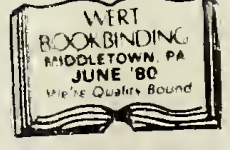


